\title{
Eutrophication Evaluation Model and Application for Reservoir Based on Fuzzy Pattern Theory
}

\author{
Cheng Yuan \\ Department of building engineering \\ Chongqing Industry \& Trade Polytechnic \\ Chongqing, China \\ dingtaohz@163.com
}

\author{
LIU Jinbao \\ Department of Water Conservancy \\ Zhejiang Tongji Vocational College of Science and Technology \\ Hangzhou, China \\ liujinbao75@163.com
}

\begin{abstract}
According to the objective fact that eutrophication degree of water body belongs to fuzzy concept, an eutrophication evaluation model is explored and is applied in this paper based on fuzzy pattern recognition model proposed by Chen Shouyu. The evaluation model considers total phosphorus (TP), total nitrogen (TN), transparency degree (SD), chlorophyll (Chla) and permanganate index (CODMn) total 5 indicators. A large reservoir for water supply is taken as an object for carrying out the research on eutrophication evaluation based on the monitoring data in the period of 20052008. The eutrophication evaluation results show eigenvalues of annual average are respectively $2.8290,2.7177,2.8449$ and 2.5354, eigenvalues of flood period are $2.9138,2.7314$, $2.9717,2.4447$, and eigenvalues of non-flood period are $2.7483,2.7125,2.7138,2.6488$. The above results show that the reservoir is under transitional stage from mesotrophic and light eutrophication, and the proposed model for eutrophication evaluation is reasonable and satisfactory.
\end{abstract}

Keywords-eutrophication; pattern recognition; evaluation; model

\section{INTRODUCTION}

Reservoir plays a more and more important role in the water supply system for city and countryside in our country. But due to frequent human activity nearby reservoir area and socioeconomic development at the area, point-source such as daily life and industry etc., and area-source such as agriculture, soil and water loss, nearby highway and development of tourism at reservoir area etc., all these contribute negative factors to water quality and safety of the water source area of reservoir[1]. According to the survey, main water supply reservoirs in our country have been already stepped to medium, high eutrophication state, some of them tend to become worse[2-3]. Taking reference of the practice of protection for water resource, it is very clear that once the water of water source area catches such eutrophic phenomenon, it will take huge amount of money and lengthy time to recover it to normal state, such loss is too great to calculate[4].

Water environmental pollution' degree belongs to fuzzy idea, and the water quality evaluation is a relatively typical fuzzy pattern question. So this paper applies professor Chen Shouyu's fuzzy pattern recognition model[5-8] to establish eutrophication evaluation model for reservoir. It is significant to improve the water quality at water source area of reservoir, fulfill the demand of water supply, improve the ecological environment, enhance the capability of preventing and handling pollution events and monitoring of water quality.

\section{EUtrophicAtion EVALUATION MODEL BASED ON FUZZY PATTERN RECOGNITION THEROY}

Assume a sample set $X$ has $n$ water quality samples to be evaluated, and each sample has $m$ objectives, then we have the index value matrix

$$
X=\left(x_{i j}\right)_{m \times n}, i=1,2, \cdots m, j=1,2, \cdots n
$$

$m$ indexes can be evaluated according to $c$ rankings, then we get the index standard matrix

$$
Y=\left(y_{i h}\right)_{m \times c}, i=1,2, \cdots m, h=1,2, \cdots, c
$$

in which $y_{i h}$ is the standard value of index $i$ to ranking $h$.

Eutrophication degree is a fuzzy concept, and can be described as relative membership degree. Given water quality with ranking 1 is clean and $s_{i 1}=0$, with ranking $c$ is high pollution and $s_{i c}=1$, then we can get the evaluating index standard eigenvalue matrix $S=\left(s_{i h}\right)_{m \times c}$.

$$
s_{i h}=\left\{\begin{array}{cc}
0 & y_{i h}=y_{i 1} \\
\frac{y_{i h}-y_{i c}}{y_{i 1}-y_{i c}} & y_{i 1}<y_{i h}<y_{i c}, y_{i 1}>y_{i h}>y_{i c} \\
1 & y_{i h}=y_{i c}
\end{array}\right.
$$

in which $S_{i h}$ is the standard eigenvalue of index $i$ to ranking $h$,

$$
0 \leq s_{i h} \leq 1
$$

Similarly, we have the relative membership degree of indexes:

$$
r_{i j}=\left\{\begin{array}{cc}
0 & x_{i j} \leq y_{i 1}, x_{i j} \geq y_{i 1} \\
\frac{x_{i j}-y_{i 1}}{y_{i c}-y_{i 1}} & y_{i 1}<x_{i j}<y_{i c}, y_{i 1}>x_{i j}>y_{i c} \\
1 & x_{i j} \geq y_{i c}, x_{i j} \leq y_{i c}
\end{array}\right.
$$

Then we have the relative membership degree matrix $R=\left(r_{i j}\right)_{m \times n}$. Comparing $r_{i j}$ with $S$, we can get the adjacent range $\left[a_{1 j}, b_{1 j}\right], \cdots,\left[a_{m j}, b_{m j}\right]$ of $r_{i j}$, the ranking upper limit 
value $b_{j}\left(b_{j}=\max _{i} b_{i j}\right)$ and the ranking lower limit value $a_{j}\left(a_{j}=\min _{i} a_{i j}\right)$ of sample $j$. Assume the index weight vector is $W=\left(w_{1}, w_{2}, \cdots, w_{m}\right)$, and satisfies $\sum_{i=1}^{m} w_{i}=1$, $0<w_{i}<1$, then the difference between $j$ th sample and $h$ th cluster can be defined as weighted general Euclidean weighted distance, as follows.

$$
D_{h j}=u_{h j} \cdot d_{h j}=u_{h j} \sqrt{\sum_{i=1}^{m}\left[w_{i}\left(r_{i j}-s_{i h}\right)\right]^{2}}
$$

$u_{h j}$ is the relative membership degree of $j$ th sample associated with $h$ th cluster, and construct the following goal function.

$$
\begin{aligned}
& J=\min \left\{F(U, S, W)=\sum_{j=1}^{n} \sum_{h=1}^{c}\left[u_{h j}^{2} \sum_{i=1}^{m}\left(w_{i}\left(r_{i j}-s_{i h}\right)\right)^{2}\right]\right\} \\
& \text { s.t. }\left\{\begin{array}{lll}
\sum_{i}^{m} w_{i}=1, & 0<w_{i}<1 & i=1,2, \cdots, m \\
0 \leq s_{i h} \leq 1 & & h=1,2, \cdots, c \\
\sum_{h=1}^{c} u_{h j}=1 \quad \sum_{j=1}^{n} u_{h j}>0 & 0 \leq u_{h j} \leq 1 & j=1,2, \cdots, n
\end{array}\right.
\end{aligned}
$$

Construct Lagrange function

$$
\begin{aligned}
& L\left(U, S, W, \lambda_{1}, \lambda_{2}\right)= \\
& \quad \sum_{j=1}^{n} \sum_{h=1}^{c} u_{h j}^{2}\left[\sum_{i=1}^{m}\left(w_{i}\left(r_{i j}-s_{h}\right)\right)^{2}\right]-\lambda_{1}\left(\sum_{h=1}^{c} u_{h j}-1\right)-\lambda_{2}\left(\sum_{i=1}^{m} w_{i}-1\right)
\end{aligned}
$$

let $\frac{\partial L}{\partial u_{h j}}=0, \frac{\partial L}{\partial \lambda_{1}}=0$ and $\frac{\partial L}{\partial \lambda_{2}}=0$

Then solve the functions above, we get $u_{h j}$ ( the relative membership degree of $j$ th sample associated with $h$ th cluster)

$$
u_{h j}=\left\{\begin{array}{l}
0 \quad, \quad<a_{j}, h>b_{j} \\
\frac{1}{\sum_{k=a_{j}}^{b_{j}} \frac{\sum_{i=1}^{m}\left[w_{i}\left(r_{i j}-s_{i h}\right)\right]^{2}}{\sum_{i=1}^{m}\left[w_{i}\left(r_{i j}-s_{i k}\right)\right]^{2}}}, a_{j} \leq h \leq b_{j}, d_{h j} \neq 0 \\
1 \quad, d_{h j}=0
\end{array}\right.
$$

For each sample $j$, the equation of eutrophication eigenvalue is

$$
H_{j}=\sum_{h=1}^{c} h u_{h j}
$$

\section{CASE STUDY}

A large reservoir for water supply is taken as an object for carrying out the research on eutrophication evaluation based on the monitoring data in the period of 2005-2008. The five indicators are used as model evaluation index including total phosphorus (TP), total nitrogen (TN), transparency degree (SD), chlorophyll (Chla) and permanganate index (CODMn).

Each index value of water quality in TABLE I is the annual average, flood period average and non-flood period average. The standards (GB3838-2002) for water environmental quality of the above seven index are listed in TABLE II.

TABLE I. MONITORING DATA OF WATER QUALITY OF THE RESERVOIR DURING 2005-2008 (MG/L)

\begin{tabular}{|c|c|c|c|c|c|c|}
\hline \multirow{2}{*}{ Indicators } & \multicolumn{3}{|c|}{2005} & \multicolumn{3}{c|}{$\mathbf{2 0 0 6}$} \\
\cline { 2 - 7 } & $\begin{array}{c}\text { Annual } \\
\text { average }\end{array}$ & flood & Non-flood & $\begin{array}{c}\text { Annual } \\
\text { average }\end{array}$ & flood & Non-flood \\
\hline $\mathrm{TP}$ & 0.017 & 0.017 & 0.017 & 0.023 & 0.023 & 0.023 \\
\hline $\mathrm{TN}$ & 1.60 & 2.10 & 1.11 & 1.04 & 0.92 & 1.16 \\
\hline $\mathrm{Chla}$ & 0.057 & 0.078 & 0.049 & 0.051 & 0.065 & 0.045 \\
\hline $\mathrm{COD}_{\mathrm{Mn}}$ & 2.07 & 2.11 & 2.03 & 2.02 & 2.29 & 1.75 \\
\hline $\mathrm{SD}(\mathrm{m})$ & 1.66 & 1.63 & 1.69 & 1.74 & 1.75 & 1.74 \\
\hline \multirow{2}{*}{ Indicators } & \multicolumn{7}{|c|}{$\mathbf{2 0 0 7}$} & & \multicolumn{2}{|c|}{$\mathbf{2 0 0 8}$} \\
\cline { 2 - 8 } & $\begin{array}{c}\text { Annual } \\
\text { average }\end{array}$ & flood & Non-flood & $\begin{array}{c}\text { Annual } \\
\text { average }\end{array}$ & flood & Non-flood \\
\hline $\mathrm{TP}$ & 0.025 & 0.028 & 0.023 & 0.022 & 0.021 & 0.023 \\
\hline $\mathrm{TN}$ & 1.32 & 1.70 & 0.94 & 1.38 & 1.41 & 1.35 \\
\hline $\mathrm{Chla}$ & 0.062 & 0.087 & 0.051 & 0.041 & 0.052 & 0.036 \\
\hline $\mathrm{COD} \mathrm{Dn}_{\mathrm{Mn}}$ & 2.21 & 2.62 & 1.79 & 1.77 & 2.12 & 1.41 \\
\hline $\mathrm{SD}(\mathrm{m})$ & 1.62 & 1.52 & 1.72 & 2.03 & 2.23 & 1.83 \\
\hline
\end{tabular}

TABLE II. STANDARDS FOR WATER ENVIROMENTAL QUALITY (GB3838-2002) (MG/L)

\begin{tabular}{|c|c|c|c|c|c|}
\hline & $\begin{array}{c}\text { I } \\
\text { poor } \\
\text { nutrition }\end{array}$ & $\begin{array}{c}\text { II } \\
\text { mesotrophi } \\
\text { c }\end{array}$ & $\begin{array}{c}\text { III } \\
\text { light } \\
\text { eutrophica- } \\
\text { tion }\end{array}$ & $\begin{array}{c}\text { IV } \\
\text { moderate } \\
\text { eutrophica- } \\
\text { tion }\end{array}$ & $\begin{array}{c}\text { V } \\
\text { severe } \\
\text { eutrophica- } \\
\text { tion }\end{array}$ \\
\hline $\mathrm{TP}$ & 0.004 & 0.01 & 0.1 & 0.2 & 0.9 \\
\hline $\mathrm{TN}$ & 0.05 & 0.1 & 1 & 2 & 9 \\
\hline Chla & 0.001 & 0.002 & 0.026 & 0.064 & 0.4 \\
\hline $\mathrm{COD}_{\mathrm{Mn}}$ & 0.4 & 1 & 8 & 10 & 40 \\
\hline $\mathrm{SD}(\mathrm{m})$ & 5 & 3 & 0.5 & 0.4 & 0.2 \\
\hline
\end{tabular}

Here, eutrophication evaluation results of the reservoir for annual average, flood period average and non-flood period average are listed in TABLE III.

The eutrophication evaluation results show eigenvalues of annual average are respectively 2.8290, 2.7177, 2.8449 and 2.5354, eigenvalues of flood period are 2.9138 , $2.7314,2.9717,2.4447$, and eigenvalues of non-flood period are $2.7483,2.7125,2.7138,2.6488$. The above results show that the reservoir is under transitional stage from mesotrophic and light eutrophication. 
TABLE III. RESULTS OF EUTROPHICATION EVALUATION (EIGENVALUE) DURING 2005-2008

\begin{tabular}{|c|c|c|c|c|}
\hline & $\mathbf{2 0 0 5}$ & $\mathbf{2 0 0 6}$ & $\mathbf{2 0 0 7}$ & $\mathbf{2 0 0 8}$ \\
\hline $\begin{array}{c}\text { Annual } \\
\text { average }\end{array}$ & 2.8290 & 2.7177 & 2.8449 & 2.5354 \\
\hline $\begin{array}{c}\text { Flood } \\
\text { average }\end{array}$ & 2.9138 & 2.7314 & 2.9717 & 2.4447 \\
\hline $\begin{array}{c}\text { Non-flood } \\
\text { average }\end{array}$ & 2.7483 & 2.7125 & 2.7138 & 2.6488 \\
\hline
\end{tabular}

\section{CONCLUSION}

This paper introduces fuzzy pattern recognition model proposed by professor Chen to eutrophication evaluation for a large reservoir for water supply based on the fact that pollution degree is a fuzzy concept. The eutrophication evaluation results show eigenvalues of annual average, flood period average and non-flood period average between 2 and 3. The results show that the reservoir is under transitional stage from mesotrophic and light eutrophication. The evaluation results from case study show that the proposed model is feasible, applicable and satisfactory.

\section{REFERENCES}

[1] Y. Fang, X. Yang, and P. Pu, "Eutrophication and countermeasures of ecological management in Liyang Reservior,” Journal of Soil and Water Conservation, vol. 18, Dec. 2004, pp. 183-186.

[2] C. X. Zhu, and Z. T. Zhu, "Predictive study on total nitrogen and phosphor of water body in Longhekou reservoir," Journal of Anhui Agri, vol. 34, Feb. 2006, pp. 746-750.

[3] J. H. Ding, C. H. Wang, X. C. Zhou, X. X. Liang, and J. D. He, “On the characteristics of nitrogen and phosphorus in the sediments of Jinyang lake,” Journal of Safety and Environment, vol. 8, Mar. 2008, pp. $14-17$.

[4] L. Li, H. Wang, X. H. Zhang, and Y. J. Ma, "Research on Internal phosphorus release of lakes with different sediment system," China Water \& Wasterwater, vol. 23, Sep. 2007, pp. 76-79, 83.

[5] S. Y. Chen, G. L. Wang, W. G. Zhang, and C. L. Li, "Fuzzy pattern recognition model for water quality evaluation and its application on Biliu reservoir,” Research of Environmental Sciences, vol. 12, Apr. 1999, pp. 42-45.

[6] S. Y. Chen, "Fuzzy pattern recognition model with cross iteration and its convergence,” Journal of Dalian University of Technology, vol. 41, Mar. 2001. pp. 264-267.

[7] S. Y. Chen, J. X. Yuan, Y. W. Li, "Fuzzy clustering iterative model and it s application based on variable fuzzy set," Journal of Dalian University of Technology, vol. 48, Nov. 2008, pp. 881-886.

[8] S. Y. Chen, Y. Guo, "Variable fuzzy sets and its application in comprehensive risk evaluation for flood control engineering system," Fuzzy Optimization and Decision Making, vol. 5, Apr, 2006, pp. 153162. 